\title{
Prevention of needle stick injuries during irrigation in oral \& maxillofacial surgery by a simple technical Modification
}

\author{
Naveen Chhabra', Samit Jain², Shruti Chhabra ${ }^{1}$ \\ 'DAV Dental College \& Hospital, Yamunanagar, India \\ ${ }^{2}$ Uttranchal Dental and Medical Research centre, Dehradun, India
}

doi: 10.3396/ijic.V7i4.038.11

Irrigation is defined as the cleaning of a wound or body organ by flushing or washing out, with water or a medicated solution. ${ }^{1}$ The purpose of irrigation is cleansing, disinfection and cooling of tissues. In Oral and Maxillofacial surgery, irrigation is mainly used for wound cleansing, for lavage of space infections and in bone cutting. Syringes and needles are the most commonly used irrigation equipments, with a standard specification of 18-19G needle and 30-35 cc syringe. ${ }^{2}$ Syringes and needles, when used, often add a risk of needle stick injuries which is a major cause of concern. The risk of blood borne infections during irrigation due to needle stick injuries possesses to be a health hazard to healthcare workers in hospitals, clinics, and labs. Here, we recommend a simple technique for irrigation to be used in maxillofacial practice using the same syringes and needles without any risk of needle stick injury.

\section{Technique}

The cap of the needle is longer than the needle (Fig. 1) by about $4 \mathrm{~mm}$ that can be cut at the tip with the help of scissors (Fig. 2). After cutting the needle cap, make sure that there are no sharp edges of the needle cap visible to the naked eye. However on microscopic level their might be some uneven edges present. Though the chances of soft tissue injuries are very low they cannot be negated. The remaining length of the cap still remains more than the needle by approximately $2 \mathrm{~mm}$ (Fig. 3). Now this syringe can be used for irrigation without any risk of needle stick injury generating the same pressure as before (Fig. 4).

The merits using this technique during irrigation are:

1. Prevention of needle stick injuries

2. Less micro-aerosol formation and thus reduction in splash during irrigation

3. Needle length is maintained for deeper tissue irrigation

4. Irrigation is accomplished maintaining same pressure

5. No additional cost

The only demerit using this technique is that the bending of the needle, which is required for accessibility in some areas like in maxillary posterior region, is not possible.

\section{Corresponding author}

Samit Jain

Uttranchal Dental and Medical Research centre, Dehradun, India

Email: drsamitjain@yahoo.com 


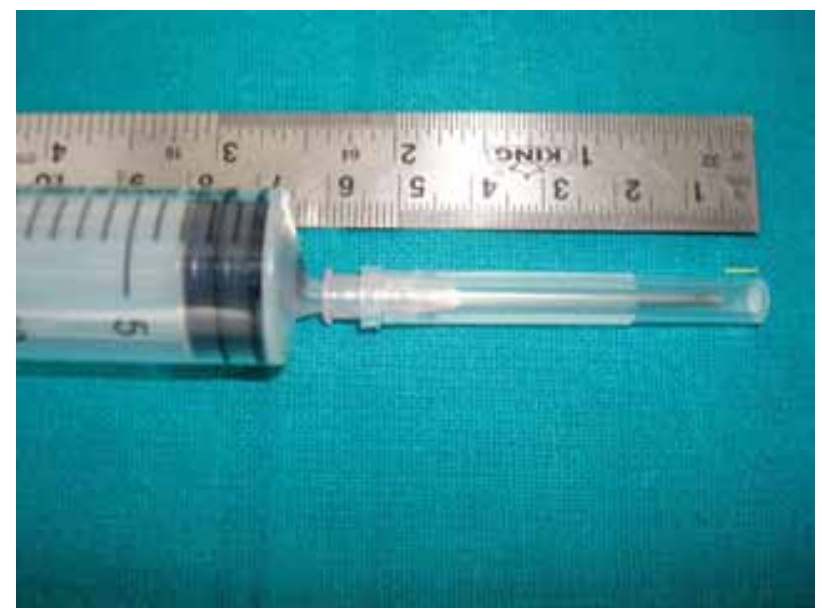

Figure 1: The cap of the needle is longer than the needle

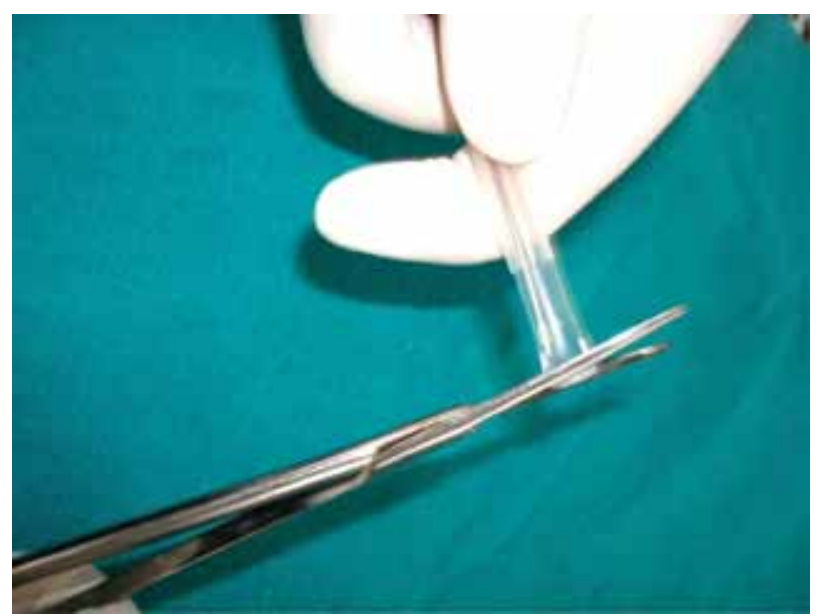

Figure 2: The cap can be cut at the tip with the help of scissors

\section{Discussion}

In oral and maxillofacial surgery, irrigation is mainly used for wound cleansing, for lavage of space infections and in bone cutting to prevent heat production and maintain temperature below $56^{\circ} \mathrm{C}$, beyond which irreversible bone damage occurs. ${ }^{3}$ Syringes and needles are the most commonly used irrigation equipments, with a standard specification of 18-19G needle and 30-35 cc syringe. ${ }^{2}$ They generate a optimum irrigation pressure of 8-12 psi which effectively cleanses the wound, reduces wound trauma and wound infection. ${ }^{2}$ Other syringes commonly in use i.e. $6 \mathrm{cc}, 12 \mathrm{cc}$ and 35 cc with a $19 \mathrm{G}$ needle produce a pressure of 30 , 20 and 8 psi respectively. ${ }^{4}$ High irrigation pressure i.e. $>15$ psi, if used for irrigation can cause wound trauma and drive bacteria into the tissue.

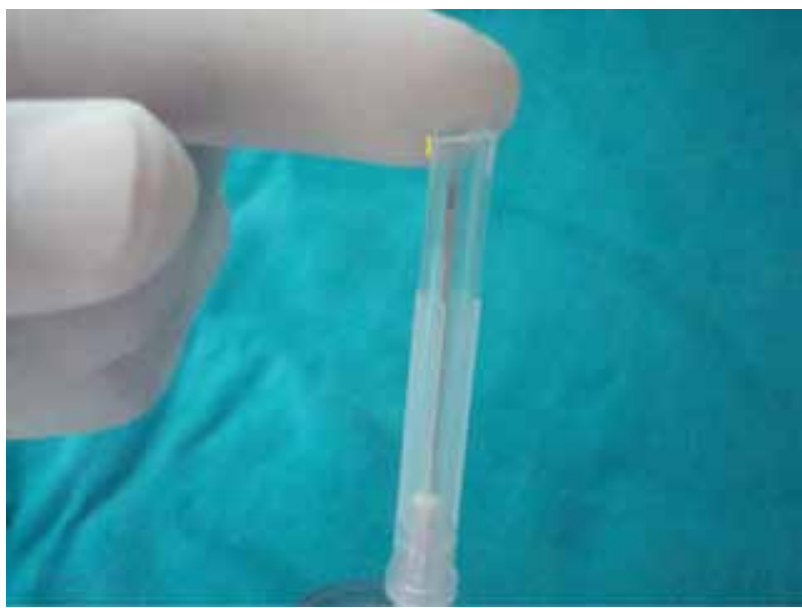

Figure 3: The remaining length of the cap still remains more than the needle by approximately $2 \mathrm{~mm}$

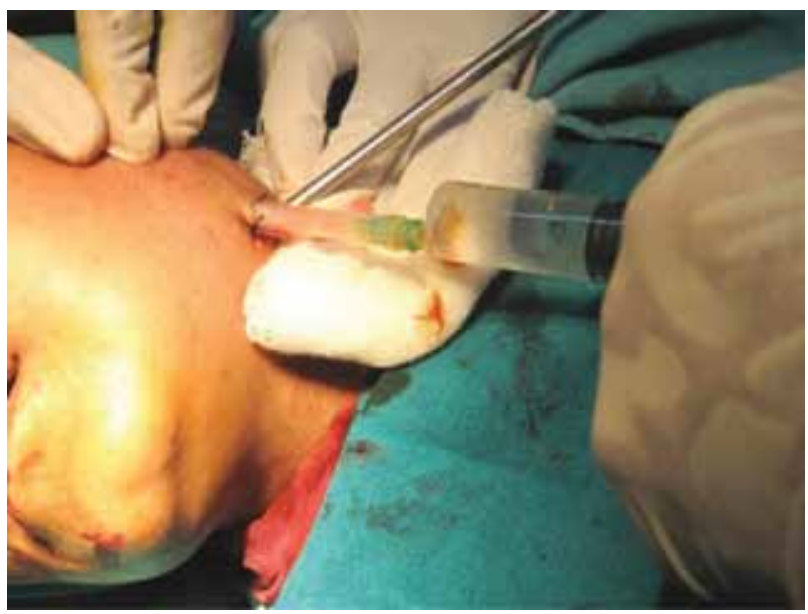

Figure 4: This syringe can be used for irrigation without any risk of needle stick injury

The syringes and needles also add to the risk of needle stick injuries, a major cause of concern. The risk of blood borne infections during irrigation due to needle stick injuries poses a health hazard to healthcare workers in hospitals, clinics, and labs. Healthcare workers incur 2 million needle stick injuries (NSIs) per year that result in infections with hepatitis $B, C$ and HIV. The World Health Organization estimates the global burden of disease from occupational exposure to be $40 \%$ of the hepatitis B and C infections and $2.5 \%$ of the HIV infections among health care workers. ${ }^{5}$ Needle injuries mainly occur during suturing (52\%), loading $(11 \%)$, passing $(13 \%)$, recapping $(3 \%)$, cleaning up $(3 \%)$ and others $(17 \%) .{ }^{4}$ Needle injury is more common with solid bore ( $81 \%$ ) than hollow bore (19\%) needles. ${ }^{4}$ 
There are numerous other technical modifications in the literature like blunt tip needles (Ethiguard) ${ }^{7}$ and monoject ${ }^{\mathrm{TM}}$ syringes (Kendall healthcare) which are capable for irrigation, but their availability is limited and they are costlier. In some health centers, off the record practices such as cutting the needle at its junction with the hub is used for prevention of needle stick injuries but this modification comes with disadvantages like a less focused stream, unpredictable pressure generated due to narrowing of the lumen of the needle and above all it impairs the ability to irrigate the deep surgical sites as the advantage of $25-30 \mathrm{~mm}$ needle length is lost.

Thus this procedure is a simple modification to be brought about in the needle during irrigation without any change in design as well as no financial implications except in cases where needle bending is required for accessibility.

\section{References}

1. Definition: Irrigation [online]. [2008] [cited 2009 Aug 6]; Available from: http://www.dict.org/bin/Dict?Form=Dict2\&D atabase $=w n \& Q u e r y=$ irrigation .

2. Baranoski S, Ayello EA. Wound care essentials. $2^{\text {nd }}$ ed. Philadelphia Pa: Lipincott, Williams and Wilkins: 2007, p. 109.

3. Peterson LJ, Ellis E, Hupp JR, Tucker MR Contemporary Oral and Maxillofacial Surgery. $4^{\text {th }}$ ed. Maryland Heights, Miss. Mosby (Elsevier): 2002, p. 308.

4. King C., Henretig FM Textbook of Pediatric emergency procedures. $2^{\text {nd }}$ ed. Philadelphia Pa:Lipincott, Williams and Wilkins: 2007. p. 57.

5. Sagoe CM, Pearson JD, Perry J, Jagger J. Risks to health care workers in developing countries. N Engl / Med 2001; 345: 538-539. http://dx.doi.org/10.1056/NEJM200108163450711

6. NIOSH Alert: preventing needlestick injuries in health care settings. Washington, DC: National Institute for Occupational Safety and Health, 1999. (Publication no. 2000-108.)

7. Aisaka K, Itabashi K, Nagasaka K, Kuroda K, Arita S, Takane V. Influence of Novel Blunt Needles (Ethiguard) on Safety for Gynecologic Operations. Obstet Gynecol 2008; 109(4[suppl]): $25 \mathrm{~S}$. 